\title{
O Agir Militante em um Projeto de Extensão com a Comunidade Surda
}

\section{The Political Activism in an Extension Project With the Deaf Community}

\section{El Actuar Militante en un Proyecto de Extensión con la Comunidad Sorda}

\footnotetext{
(iD) 9

Nubia Garcia Vianna

Universidade Estadual de Campinas

(iD)

Janice Gonçalves Temoteo Marques Universidade Estadual de Campinas
}

Resumo: Surdos usuários da Língua Brasileira de Sinais convivem com barreiras linguísticas, comunicacionais e atitudinais nos serviços de saúde de todo o Brasil. Este artigo trata-se do relato de experiência autoetnobiográfico de uma docente-pesquisadora, a partir de suas afetações e implicações, e de como elas se reverberaram na escrita de um projeto de extensão. O relato se dá em três momentos: o primeiro, aborda as afetações vividas pela pesquisadora antes e durante o desenvolvimento de uma de suas pesquisas; o segundo, discorre sobre seu agir militante e implicado com a comunidade surda para além do espaço universitário e, o terceiro, a construção coletiva que caracterizou a escrita do projeto de extensão. $O$ processo descrito evidencia que, do início ao fim, o projeto se constituiu como uma ação dialógica entre comunidade e universidade 
e constatamos que foi o agir militante da docente-pesquisadora o principal mote para desencadear o processo de construção do projeto de extensão.

Palavras-chave: Surdez. Surdos. Direito à Saúde. Participação Social. Extensão Comunitária.

Abstract: Deaf people who use the Brazilian Sign Language experience linguistic, communication and attitudinal barriers in health care throughout Brazil. This article discusses the report of an autoethnobiographic experience of a teacher-researcher, based on her affectations and implications, and on how these aspects impact the writing of an extension project. The report is approached from three different moments: the first addresses the affectations experienced by the researcher before and during the development of a research project; the second moment discusses her political activism and her

2 involvement with the deaf community beyond the university environment and, finally, the third moment reports the collective construction that characterized the writing of the extension project. The described process proves that the project as a whole was constituted as a dialogical action between community and university, and it can be noticed that the political activism of the teacher-researcher was the main triggering factor in the development process of the extension project.

Keywords: Deafness. Deaf. Right to Health. Social Participation. Community Outreach.

Resumen: Sordos signistas conviven con barreras linguisticas, comunicacionales y actitudinales en los servicios de salud de todo Brasil. Este artículo es un relato de experiencia autoetnobiográfico de una docente-investigadora, desde sus afectaciones e implicaciones, y de cómo ellas si reverberaron en la escrita de un proyecto 
de extensión. El relato ocurre en tres momentos: el primero, aborda las afectaciones vividas por la investigadora antes y durante el desarrollo de una de sus investigaciones; el segundo, discurre sobre su actuar militante e implicado con la comunidad sorda más allá del espacio universitario y, el tercero, la construcción colectiva que caracteriza la escrita del proyecto de extensión. El proceso descrito evidencia que, del inicio al fin, el proyecto se constituyó en una acción dialógica entre la comunidad y la universidad y constatamos que fue el actuar militante de la docente-investigadora el principal hecho que hizo desencadenar el proceso de construcción del proyecto de extensión.

Palabras clave: Sordera. Sordo. Derecho a la Salud. Participación Social. Extensión Comunitaria.

3

Data de submissão: 20/11/2020

Data de aprovação: 08/12/2020 


\section{Introdução}

A universidade é uma instituição social que tem como função colaborar no processo de construção do conhecimento. É um espaço não apenas reconhecido, como eleito culturalmente, para esclarecer, discernir e problematizar, questões vivenciadas na sociedade, a partir de uma análise crítica e, acima de tudo, ética.

O exercício da docência tem cada vez mais exigido um maior protagonismo enquanto ator político e social, em que o papel do professor vai para muito além daquele desempenhado na sala de aula. Características como falta de vínculo ou descompromisso com a realidade não atendem aos anseios de uma universidade pública, nem as complexas demandas da sociedade, sobretudo, nos dias atuais. Para tanto, valorizar os três principais eixos da universidade (ensino, pesquisa e extensão) é fundamental.

Sobre a definição do que se considera extensão na Educação Superior, a Resolução n.7 do Ministério da Educação, define como sendo:

[...] a atividade que se integra à matriz curricular e à organização da pesquisa, constituindo-se em processo interdisciplinar, político educacional, cultural, científico, tecnológico, que promove a interação transformadora entre as instituições de ensino superior e os outros setores da sociedade, por meio da produção e da aplicação do conhecimento, em articulação permanente com o ensino e a pesquisa (BRASIL, 2018).

Esta mesma resolução apresenta a concepção e as diretrizes que norteiam as atividades extensionistas no âmbito do ensino superior, sendo uma delas "a interação dialógica da comunidade acadêmica com a sociedade por meio da troca de conhecimentos, 
da participação e do contato com as questões complexas contemporâneas presentes no contexto social" (BRASIL, 2018).

Dentre tantas questões complexas existentes na sociedade, uma delas é o tema dos direitos humanos das pessoas com deficiência, que são definidas pela Lei Brasileira de Inclusão, em seu Art. $2^{\circ}$, em sintonia com a Convenção Internacional sobre os Direitos das Pessoas com Deficiência, como sendo aquelas que têm

$$
\begin{aligned}
& \text { [...] impedimento de longo prazo de natureza física, mental, } \\
& \text { intelectual ou sensorial, o qual, em interação com uma ou mais } \\
& \text { barreiras, pode obstruir sua participação plena e efetiva na } \\
& \text { sociedade em igualdade de condições com as demais pessoas } \\
& \text { (BRASIL, 2015). }
\end{aligned}
$$

Neste grupo, no rol das ditas deficiências sensoriais, existe o 5 segmento de pessoas com deficiência auditiva e, dentro dele, uma parcela que se autointitula Comunidade Surda e que compõe uma minoria linguística, por fazerem uso da língua de sinais.

Este grupo considera que a língua de sinais como sua principal característica e aquilo que constitui o indivíduo surdo, permitindo compartilhar vivências sociais, crenças, valores culturais e estabelecer conexões com a sociedade na qual está inserido (CHAVEIRO et al., 2020). Trata-se de uma discursividade embasada no discurso socioantropológico da surdez, que atribui ao uso da língua de sinais aquilo que mais fortemente influencia na construção da subjetividade do indivíduo e a principal marca da cultura surda (CARVALHO e MARTINS, 2016).

Do outro lado, está o discurso clínico-terapêutico, que compreende a surdez como um déficit anátomo-fisiológico manifestado pela perda auditiva que demanda medidas de reparação (RODRÍGUEZ-MARTíN et al., 2020). Ser surdo é visto como deficiência; 
lógica esta que corresponde a um regime de verdade que é o do corpo que falta algo e que, por isso o indivíduo encontra-se em situação de desvantagem perante os que ouvem (CARVALHO e MARTINS, 2016). Este discurso que combina com o da deficiência pautado por um modelo biomédico, inclui o sujeito surdo usuário de língua de sinais neste grupo populacional, sem necessariamente considerar o uso de uma outra língua que não a oral como sua principal característica.

No Brasil, não existem dados censitários sobre as pessoas usuárias de língua de sinais. O censo apontou que 9.722.163 de brasileiros são pessoas com deficiência auditiva e estima-se que os surdos usuários de língua de sinais estejam concentrados na estratificação que correspondem aqueles que responderam que não conseguem ouvir de modo algum e os que ouvem com grande dificuldade, o que representa um total de 2.147 .366 de pessoas (BRASIL, 2014).

Acessibilidade linguística e comunicacional, para estas pessoas é um direito em si mesmo, mas, também, um direito meio, cuja ausência impede o exercício de outros direitos humanos fundamentais, como o direito à saúde.

Quando as barreiras linguísticas, comunicacionais e atitudinais se expressam na área da saúde podemos dizer que este direito se encontra ameaçado. A negação do direito que se expressa cotidianamente pela dificuldade ou impossibilidade da pessoa surda interagir na sua língua ao acessar o sistema de saúde é uma questão complexa. Discussões em torno desse tema, é o que tem motivado muitas das pesquisas da primeira autora deste texto, sobretudo, de sua tese de doutorado $(X X, X X)$, e foi, a partir do acúmulo, das inquietações e do amadurecimento proporcionados por estas pesquisas, que surgiu o projeto de extensão intitulado Fortalecimento da Comunidade Surda: saúde como direito. 
O Agir Militante em um Projeto de Extensão com a Comunidade Surda Nubia Garcia Vianna • Janice Gonçalves Temoteo Marques

Este artigo tem, portanto, o objetivo de relatar a experiência da pesquisadora, a partir de suas afetações e implicações, e de como elas se reverberaram e desencadearam um processo de construção coletiva e dialógica, cujo produto foi a escrita de um projeto de extensão. Não se pretende neste texto relatar a execução da atividade extensionista, até porque ela ainda não foi colocada em prática, mas, relatar a construção do projeto, momento não menos importante que sua realização, uma vez que exigiu construção de vínculos, envolvimento da comunidade acadêmica e do segmento da sociedade envolvido.

\section{Notas Teórico-Metodológicas}

Este texto se configura como um relato de experiência, inspirado na autoetnografia de uma das autoras deste manuscrito, atualmente docente-pesquisadora da Universidade XX, do Estado de XX. Será relatado, em primeira pessoa, o encontro da docente-pesquisadora com a comunidade surda, desencadeado por afetações experenciadas antes e durante sua tese de doutoramento até o desdobramento em projeto de extensão.

A palavra autoetnografia surgiu nos anos 70, mas foi na década de 90 que passou a ganhar mais destaque nas ciências sociais. Dentro das pesquisas qualitativas, a autoetnografia surge como um método que valoriza a experiência pessoal do pesquisador no processo de construção do conhecimento, permitindo que o pesquisador se envolva e que as emoções que emergem do encontro com o campo também sejam consideradas na análise do objeto de estudo. (MAGALHÃES, 2018).

A autoetnografia é uma forma privilegiada de pesquisa por permitir a reflexibilidade sob a ótica do pesquisador aliada à sua 
O Agir Militante em um Projeto de Extensão com a Comunidade Surda Nubia Garcia Vianna • Janice Gonçalves Temoteo Marques

própria experiência. Para Adams et al (2015, p.30), a "reflexibilidade consiste em nos voltarmos para nossas experiências, identidades e relações a fim de considerarmos como elas influenciam nosso trabalho presente".

Durante o relato de experiência também utilizaremos pressupostos teóricos da análise genealógica, tendo Foucault como nosso principal intercessor, considerando que o corpo social é fruto de tensões, relações de forças e múltiplos interesses, permanentemente imersos em práticas discursivas e não discursivas (FOUCAULT, 2010).

Dessa forma, nos autorizamos a compartilhar o vivido, mesclando a experiência individual com o olhar científico das autoras, buscando melhor compreensão dos fenômenos culturais e linguísticos que permeiam o mundo da pesquisa, da extensão e do ensino no qual ambas estão imersas.

8

\section{Relato de Experiência: Implicações de uma Docente-Pesquisadora}

O presente relato de experiência se dará em três momentos: o primeiro, abordará as afetações vividas pela pesquisadora antes e durante o desenvolvimento de sua pesquisa de doutorado; o segundo, discorrerá sobre seu agir militante e implicado com a comunidade surda para além do espaço universitário e, o terceiro, a construção coletiva e dialógica que caracterizou a escrita do projeto de extensão propriamente dito.

\section{Minha História que Não é Minha: Motivações para a Pesquisa Científica}

Em uma reunião do grupo de pesquisa do qual faço parte, foi proposto que cada um dos presentes contasse uma história, 
verdadeira ou não, explicando as razões pelas quais havíamos escolhido o tema de pesquisa em curso. E, assim, comecei.

Venho de uma família pequena formada por minha mãe, eu, filha caçula, meu irmão e minha irmã, com 16 e 19 anos de diferença em relação a mim, respectivamente. Éramos uma família um pouco atípica, em comparação com as outras que eu conhecia. Meu irmão era surdo! Ele contraíra meningite nos primeiros meses de vida e, em um dia ele era ouvinte e, no outro, não. Passei a infância ouvindo as histórias dramáticas de dificuldades vividas por ele e minha mãe. Na época da infância dele, década de 60, nem existia Sistema Único de Saúde (SUS) e o acesso a médicos, exames, etc. era bastante complicado. Acho que a perda auditiva só foi percebida rapidamente porque minha mãe logo notou as mudanças de comportamento. Eles passaram a frequentar o Instituto Nacional de Educação de Surdos (INES), que existe até hoje no Rio de Janeiro, em um bairro bastante longe de onde morávamos. Ela atravessava a cidade com ele, numa persistência dessas próprias de mãe. Lá ele estudava e era atendido por profissionais que tentavam ensiná-lo a falar. Meu irmão conseguiu o primeiro aparelho auditivo por uma "vaquinha" de familiares e amigos. A alegria com a chegada do aparelho logo se transformou em frustração. Meu irmão, que era surdo profundo, passou a ouvir alguns sons, mas não tudo, muito menos com clareza, o que mais o perturbava que ajudava. Foi feito de tudo um pouco para que ele ouvisse e falasse, sem sucesso. Na instituição, ele também aprendeu a "falar com as mãos". Era assim que eu me referia, quando criança, à língua de sinais. Na verdade, ele aprendeu os sinais muito mais com os outros surdos que conheceu por lá que no próprio INES. Inevitavelmente nós, em casa, também aprendemos esta língua e tudo começou a meIhorar. Quando eu nasci, eles já usavam os sinais e para mim foi natural aprendê-los. Também me lembro de ver o tal aparelho auditivo, sempre dentro da gaveta e, volta e meia, minha mãe dizendo para que ele o colocasse. Lembro bem da época em que ele estava procurando emprego. Chegava em casa contando sobre as atitudes de preconceito e discriminação que passava em seu dia. Sofríamos por ele. Sofríamos com ele. E 
eu, sofria por todos os surdos que, como meu irmão, viviam situações como aquela. Foi daí que surgiu a minha escolha pela fonoaudiologia e por pesquisas como esta na área da surdez, que estou desenvolvendo na minha tese de doutorado. Eu analiso a surdez na política de saúde para a pessoa com deficiência.

Assim, concluí, dizendo meu objeto de pesquisa. A história que foi escutada atentamente pela outra pesquisadora, foi ganhando vida e sentidos, porém, acabara de ser inventada por mim. Afinal eu tinha o aval, dado pelos pesquisadores que conduziam a atividade, de que ela podia ser real ou não. Quis "brincar" com um clichê que há tempos escuto sobre a associação entre a escolha pelo tema e ter alguém com deficiência na família. Precisa haver algum surdo na família para qualquer pesquisador se conectar ou se importar com eles? A condição da surdez ou da deficiência parece distante de nós. Tão distante que se torna atípico motivar-se pelo tema, se não há alguém na família. Contudo, a surdez ou a deficiência, nos ronda, nos espreita e mora no exato instante da nossa distração. Se havia uma parte bastante verdadeira na história era a que meu irmão havia tido meningite. Por muito pouco, $a$ história que não é minha podia ter sido.

Ao mesmo tempo, a história que não era minha também era minha. A narrativa era um mix de fatos que um dia me foram contados na clínica. Elas me desterritorializaram no meu fazer fonoaudiológico. Eu, que não sabia quase nada sobre a fonoaudiologia, escolhera esta profissão porque supostamente me colocaria em contato com os surdos e, consequentemente, com a língua de sinais. Eu mal sabia o quão complexo era o universo em que estava me propondo a entrar e que a fonoaudiologia, na sua relação com a surdez, surgira de práticas opostas ao que me motivou a escoIhê-la como profissão. 
A fonoaudiologia surge das transformações históricas da figura do professor especializado, que tinha por função desenvolver um trabalho, simultaneamente, pedagógico e terapêutico com os chamados alunos especiais diagnosticados com desvios na fala. Deste professor, passou-se a exigir, além de um conhecimento pedagógico, um saber médico, que o tornasse capaz tanto de identificar, diagnosticar quanto de exercer uma terapêutica cujo foco era a correção e volta à normalidade (OLIVEIRA, 2002).

A vontade de trabalhar com surdos nunca foi pelo déficit auditivo em si. Eu me conectava à surdez porque me afetava por uma outra forma de se subjetivar. Boa parte das histórias que me foram contadas durante a atuação como fonoaudióloga ecoam até hoje. Creio que só pude conhecer estas histórias e me deixar afetar por elas porque, enquanto terapeuta, consegui deixar de me fixar no padrão de qualidade fonoarticulatório e de querer imprimir-lhes uma norma. Fomos inventando outros modos de interação, muitas vezes mediados pela língua de sinais, outras vezes, não. Tudo dependia das possibilidades, da necessidade e do desejo do usuário. Era nessas vezes de criação conjunta que sentia a potência da fonoterapia. Sentia que era preciso ressignificar a clínica, a terapêutica e colocá-la em análise, assim como esse saber fonoaudiológico que acionava.

Somado a isto, me inquietavam os problemas existentes no campo da Saúde Coletiva, que transversalizam todo o SUS e atingem a população, seja de surdos ou ouvintes, como dificuldades de acesso às tecnologias de cuidado, como a exames, procedimentos ou aos profissionais e seus conhecimentos. Quando o usuário consegue ultrapassar tais barreiras e acessa o sistema, problemas da ordem do cuidado integral entram em cena. A questão estava muito além da relação oferta e demanda e era preciso entender alguns porquês. 
As primeiras buscas por respostas foram empreendidas debruçando-se nos documentos normativos do Ministério da Saúde (MS), ficando evidente o esforço do sistema em ofertar acesso às tecnologias reparadoras da audição, porém, com pouca ênfase ou valorização dos processos terapêuticos. Além disso, havia uma total ausência da Língua Brasileira de Sinais (Libras) nos documentos do MS, num misterioso silêncio, quase tão grande quanto o da própria língua em ato.

A invisibilidade da Língua de Sinais nas políticas públicas de saúde para a pessoa com deficiência parecia ser apenas a ponta do iceberg de algo mais profundo. Parecia não fazer sentido existir uma política de saúde para a pessoa com deficiência que não considerasse que, algumas delas, deviam ter seu modo de interagir no mundo mediado pela Língua de Sinais.

Estas inquietações me levaram da clínica para a gestão na Coordenação-Geral de Saúde da Pessoa com Deficiência do MS. Ao trabalhar neste lugar, não vou negar que existia um desejo de contribuir para algo que achava estar faltando na política pública de saúde. Compreendi que uma portaria do MS é produto das relações de forças e disputas de poder de diversos atores sociais, podendo gerar políticas e ações mais ou menos inclusivas.

Se eu quisesse que os meus desejos mais íntimos fossem escutados, não seria com minha própria voz. Era preciso falar dos focos de poder publicamente, o que por si só já seria uma luta. Poder definido por Foucault (2010) não como um fato em si, mas, antes de tudo, como "um modo de ação de alguns sobre os outros", só possível de existir em ato. Nas palavras de Foucault (2010), poder

\section{[...] éum conjunto de ações sobre ações possíveis; ele opera sobre o campo de possibilidades onde se inscreve o comportamento dos sujeitos ativos; ele incita, induz, desvia, facilita ou torna}


mais fácil, amplia ou limita, torna mais ou menos provável; no limite, ele coage ou impede absolutamente, mas é sempre uma maneira de agir sobre um ou vários sujeitos ativos, e o quanto eles agem ou são suscetíveis de agir. Uma ação sobre ações (FOUCAULT, 2010, p.243).

Tinha certeza que o que eu avaliava faltar na política de saúde para os surdos fazia sentido para eles, mas quem precisava dizer isso eram eles mesmos. Era preciso mergulhar em um agir militante, sem o qual qualquer pesquisa nessa área corria o sério risco de perder seu sentido.

Passara a conceber a produção do conhecimento como um processo em que o pesquisador se assume não apenas interessado, mas implicado com seu objeto de pesquisa, deixando aparecer em sua narrativa suas experiências, seus afetos e como eles desencadeiam uma gama de reflexões sobre o que se quer pôr em análise.

Não é somente reconhecer-se não neutro e, a partir disso, valorar algumas coisas e outras não, fazer certas escolhas ou não. É para além disso. É pôr-se em análise junto com o que se quer analisar. É reconhecer-se dentro do próprio campo analítico. Pesquisador e objeto já se confundem, se misturam, não são mais partes separadas (CERQUEIRA et al, 2014; ABRAHÃO et al, 2014). Nas palavras de Merhy (2004), o pesquisador está "tão implicado com a situação que, ao interrogar o sentido das situações em foco, interroga a si mesmo e à sua própria significação enquanto sujeito de todos estes processos".

A escolha do tema da surdez, portanto, não foi uma escolha aleatória, casual, muito menos neutra. Falo do que defendo, produto de muitos atravessamentos e que fazem parte do que me constitui e do que levou a realizar a tese de doutorado, defendida em 2018, e a construir o projeto de extensão Fortalecimento da Comunidade Surda: saúde como direito, em 2020. 


\section{Aproximação com a Comunidade Surda: entre a Pesquisa e a Extensão}

A pesquisa de doutorado me motivou, no último ano de escrita, em 2017, a ir onde os surdos do município de Campinas estavam. Não como quem vai a campo coletar dados de pesquisa, pois a tese era uma pesquisa documental e o encontro com surdos não era uma prerrogativa. Contudo, sem que pudesse prever, as afetações provenientes destes encontros influenciaram muitas das reflexões daquela pesquisa e se desdobraram em incômodos profundos que não podiam ficar silenciados.

O contado inicial foi com o Espaço Cultura Surda que é uma escola de ensino da Libras e, também, um lugar onde se pretende oferecer cultura, tanto para surdos como ouvintes, por meio de atividades inclusivas.

À época, eu era conselheira do Conselho Municipal de Saúde (CMS) e foi este o lugar de fala que ocupei para me dirigir ao local. Compartilhei, em uma primeira reunião com as proprietárias do Espaço, uma surda e uma intérprete, meus incômodos em relação às dificuldades vividas pelos surdos, especialmente na área da saúde e coloquei-me à disposição para levar estas questões ao pleno do Conselho de Saúde. Saber, à luz da literatura, que a falta de acessibilidade linguísticas e comunicacional se constituem em barreiras de acesso à saúde não era suficiente. Era preciso saber dos próprios surdos da cidade, o que eles pensavam e quais seriam as possíveis soluções.

Organizamos dois encontros, cada um com cerca de 20 pessoas, para compartilhar as dificuldades e pensar soluções. Foi neste momento que tomei conhecimento da existência da Associação dos Surdos de Campinas (ASSUCAMP), criada em 1962 quando sentiu-se a necessidade de ter momentos de troca de experiências, de lazer, participar de eventos esportivos e de projetos sociais. 
Desses encontros, escrevemos um documento que foi protocolado junto à prefeitura de Campinas e assinado pelo CMS, o Fórum Municipal de Direitos Humanos, o Espaço Cultura Surda e a ASSUCAMP. Nele, a gestão pública é solicitada à realizar: capacitação de profissionais de saúde sobre a surdez, não apenas sob a perspectiva médica, mas também socioantropológica, englobando assuntos, como Comunidade Surda, língua de sinais, Cultura e Identidade Surda, políticas públicas e legislação vigente, que garante o direito à saúde do surdo; campanhas de prevenção e promoção à saúde, de forma acessível, por meio da ampla divulgação em Libras; contratação de intérpretes para a Central de Interpretação de Libras e, especificamente, para hospitais públicos da cidade, entre outros pedidos.

Estes dois encontros também serviram para divulgar e incentivar a participação dos surdos na X Conferência Municipal dos Direitos da Pessoa com Deficiência, que estava para acontecer. A elaboração do documento qualificou a participação da Comunidade Surda, que levou as reivindicações para este espaço de controle social como propostas, entrando no debate e votação, como pode ser visto no Relatório Final da Conferência (CAMPINAS, 2017).

O ano de 2018 foi de inúmeras cobranças de resposta ao documento enviado à prefeitura, porém, sem muito êxito. Em 2019, ocorreram duas outras conferências municipais importantes - a $11^{\circ}$ Conferência Municipal de Saúde e a XI Conferência Municipal dos Direitos da Pessoa com Deficiência. Em um movimento semeIhante, voltei a provocar a participação dos surdos, organizando uma plenária temática antes da Conferência de Saúde. Nela, os velhos problemas foram reafirmados, as propostas foram aprimoradas, levadas e votadas nestas duas conferências, como consta no Relatório Final (CAMPINAS, 2019). 
Destas conferências, um importante desdobramento foi eleger conselheiros surdos para o Conselho Municipal dos Direitos da Pessoa com Deficiência (CMDPCD), gestão 2018-2019 e 2020-2021, bem como a primeira conselheira surda para o CMS.

Passados pouco mais de dois anos do início da articulação com a Comunidade Surda, organização e sistematização das demandas na área da saúde, pouco foi feito pela gestão pública para atendê-los. Dois avanços ocorreram neste período: a contratação de mais intérpretes para a CIL e a destinação de um profissional, responsável por cuidar dos temas específicos da área da pessoa com deficiência na cidade, algo que não existia. A partir disso, foram realizadas reuniões no âmbito da Secretaria, com a presença do CMS e do presidente da ASSUCAMP, visando construir caminhos para o cumprimento das necessidades dos surdos.

Apesar de ter aumentado a participação social da Comunidade Surda em defesa da garantia do direito à saúde, ela ainda se restringe a uma minoria e ocorre de forma assistemática. Percebe-se que há bastante clareza dos problemas que a acomete, mas pouca reflexão para ação.

Foi com base neste histórico de aproximação com a Comunidade Surda, de militância e luta pela garantia de direitos que surge a ideia de propor um conjunto de atividades que pudesse, simultaneamente, ampliar o acesso à saúde e também provocar, instigar e promover reflexão para ação. Os mecanismos de poder estavam postos e o produto continuava sendo a negação de direitos. Era preciso avançar nas estratégias de resistência. 


\section{O Projeto de Extensão como Aposta para o Fortalecimento da Comunidade Surda e a Garantia do Direito à Saúde}

Na cidade de Campinas/SP, existem 48.356 pessoas com deficiência auditiva, sendo que é estimado que os surdos usuários de Libras estejam concentrados nos estratos que responderam que ouvem com grande dificuldade e que ouvem com alguma dificuldade, totalizando, 12.030 pessoas (IBGE, 2010).

Os parâmetros quantitativos são importantes para o planejamento de ações e políticas sociais, mas eles não são os únicos. Sabemos que ter ou não espaço na agenda governamental está relacionado, sobremaneira, às assimetrias de poder que perfazem o corpo social e que as pessoas com deficiência historicamente não tem sido prioridade (VIANNA, 2018). Neste contexto, Vianna (2018) afirma que quando o outro da ação é o surdo,

[...] enquanto indivíduo ou grupo, sobre o qual o poder é exercido, o produto desta relação tem se traduzido em barreiras, sobretudo comunicacionais e atitudinais, cuja expressão é a discriminação, desigualdade e negação de direitos já há tempos legitimados (VIANNA, 2018, p.26).

Concordo com Reis e Morais (2020, p.5) que as questões referentes à luta cotidiana da pessoa surda em âmbitos educacionais e sociais ganharam olhares relevantes ao longo dos últimos anos, "porém, a discussão acerca de tais problemáticas e a busca por soluções estão submetidas a um cenário de inércia política". Assim, incomodada com o abandono e descaso do poder público perante os surdos da cidade compartilhei, novamente, com o Es- 
paço Cultura Surda, algumas estratégias de intervenção a serem desenvolvidas junto e com a comunidade surda. As ideias foram aprimoradas e levadas para Assembleia Geral da ASSUCAMP, objetivando colher sugestões e avaliar o grau de aceitabilidade da proposta que, de forma unânime, ganhou o interesse dos presentes.

Sem prever, estava começando a ser desenhado um projeto de extensão e ao me dar conta disso iniciei um processo de articulação dentro da universidade. Docentes e discentes da graduação e da pós-graduação, dos cursos de Artes Cênicas, Artes Visuais, Enfermagem, Fonoaudiologia e Música, deram suas contribuições para o projeto, que foram, posteriormente, compartilhadas, ajustadas e validadas com os surdos para a escrita da versão final.

O projeto foi, portanto, construído com o objetivo de fortalecer a Comunidade Surda de Campinas por meio do acesso à informação sobre o direito, políticas e ações de saúde. Visa, mais especificamente, compartilhar conhecimentos sobre a história da surdez, história da Comunidade Surda de Campinas, direitos e políticas sociais, participação e controle social; colaborar na difusão e no reconhecimento da língua de sinais; subsidiar o desenvolvimento de ações de prevenção de promoção à saúde; promover a interação e ação dialógica entre docentes, graduando e pós-graduandos com a Comunidade Surda, sensibilizando-os para as necessidades deste segmento da população; contribuir para a formação técnica, científica e cidadã dos envolvidos no projeto.

Para tanto, estão previstas as seguintes atividades:

\section{Setembro Surdo - mesa redonda e caminhada}

Mesa redonda em comemoração ao Dia Nacional do Surdo para apresentar e divulgar as atividades extensionistas, explicar sobre o papel da ASSUCAMP, bem como ofertar as palestras: “O 
O Agir Militante em um Projeto de Extensão com a Comunidade Surda Nubia Garcia Vianna • Janice Gonçalves Temoteo Marques

Surdo no contexto do trabalho, família e amigos" e "Corpo sinalizante: arte e cultura também é para o surdo?".

A caminhada serve para dar visibilidade ao Surdo e à Língua de Sinais, uma vez que um grande número de Surdos reunidos deve chamar a atenção das pessoas. Além deste propósito, a caminhada por si só, se configura em uma atividade física, promotora de hábito de vida saudável para controle e prevenção de doenças crônicas prevalentes.

\section{Café com Libras}

Como o próprio nome sugere, esta atividade se inicia com um café da manhã, para promover o encontro e a interação entre os surdos e demais participantes do projeto. O intuito é compartilhar conhecimentos específicos sobre a história da surdez; direitos e políticas públicas; participação e controle social; subsidiar o desenvolvimento de ações de prevenção e de promoção à saúde, bem como colaborar na difusão e reconhecimento da Língua de Sinais.

As discussões temáticas seriam acompanhadas de um momento chamado Surdos em ação, visando desencadear, por meio do Teatro do Oprimido, a emergência, reflexão e crítica sobre situações de opressão que os surdos vivem na sociedade e, simultaneamente, a busca de soluções.

Ainda dentro do Café com Libras, foi destinado um dia para promover a aproximação da Comunidade Surda com os conselheiros que os representam no CMS e CMDPCD, permitindo repasse de informações, bem como de levantamento de demandas que podem subsidiar a atuação dos conselheiros junto à comunidade surda.

\section{Papo de Homem}

Encontros com homens surdos da Federação Desportiva dos Surdos do Estado de São Paulo que se encontram para treino de 
O Agir Militante em um Projeto de Extensão com a Comunidade Surda Nubia Garcia Vianna • Janice Gonçalves Temoteo Marques

futebol. Aproveitando estes encontros, os surdos são convidados para um "bate-papo" sobre assuntos de saúde geral ou específica do homem, temas escolhidos por eles, visando a prevenção e promoção da saúde.

\section{Dia das Crianças}

Conjunto de atividades lúdicas para crianças visando explorar a criatividade, a imaginação, contato com artes, histórias infantis e brincadeiras. Visa também estimular mães, pais e outros responsáveis a reservar momentos de interação, para serem sujeitos ativos no processo de desenvolvimento de seus filhos, estimulando a linguagem e a cognição por meio do brincar. Estão previstas oficina de confecção de brinquedos e de desenho narrativo, além de palestra aos responsáveis sobre a participação da família no desenvolvimento da criança Surda.

20

\section{Workshop de Libras}

Única atividade voltada exclusivamente para ouvintes, objetiva a difusão e reconhecimento da língua de sinais, abordando os seguintes temas: iniciação aos estudos da Libras; importância do uso de classificadores e das expressões faciais na língua de sinais: elementos fundamentais para o uso da língua em contexto; regionalismos na Libras: influência dos fatores sociais, idade e escolaridade.

\section{Peça teatral}

Peça teatral Grande Duelo da Companhia de Teatro Criados Mudos, evento de encerramento. Trata-se de um teatro mudo, sendo um tipo de apresentação extremamente visual e, portanto, acessível ao público surdo. Objetiva-se, com esta peça, proporcionar acesso à atividade artística e cultural para os surdos, oferta escassa na sociedade em que vivemos. Espera-se, com este evento, 
O Agir Militante em um Projeto de Extensão com a Comunidade Surda Nubia Garcia Vianna • Janice Gonçalves Temoteo Marques

fazer uma sistematização da importância dos encontros, da sustentabilidade do projeto de extensão e da participação social dos surdos em atividades coletivas.

\section{Considerações finais}

Por meio do projeto de extensão, que nasceu como um produto do agir militante da docente-pesquisadora, buscar-se-á despertar um sentimento de coparticipação e de co-responsabilização da Comunidade Surda, dando maior protagonismo aos atores envolvidos, instrumentalizando-os sobre assuntos referentes aos direitos à saúde e políticas públicas.

O projeto tem potencial para estreitar as relações entre a Universidade e a Comunidade Surda, de modo que todos os atores são potenciais agentes indutores de transformações do coletivo, ao mesmo tempo em que é transformado por ele. O corpo docente e discente tem condições de compartilhar conhecimento científico com a comunidade, ao mesmo tempo, em que esse contato com os Surdos, traz enormes contribuições para a formação cidadã destes agentes.

A aproximação com a Comunidade Surda é extremamente enriquecedora para o estudante em formação, pois proporciona: contato com língua e cultura diferente do habitual; maior compreensão dos problemas vivenciados cotidianamente pelos Surdos.

O processo descrito traduz aquilo que consideramos ser uma premissa básica para a execução de todo projeto de extensão: ser, do início ao fim, uma ação dialógica entre comunidade e universidade. Constatamos que foi o agir militante da docente-pesquisadora o principal mote para desencadear o processo de construção do projeto de extensão, que será executado tão logo seja possível institucionalizá-lo junto à universidade e quando a pandemia de Coronavírus esteja controlada. 
O Agir Militante em um Projeto de Extensão com a Comunidade Surda Nubia Garcia Vianna • Janice Gonçalves Temoteo Marques

\section{Referências}

ABrahão, Ana Lucia; Merhy, Emerson Elias; GOMES, Maria Paula Cerqueira; TAllemberg, Claudia; ChagAs, Magda de Sousa; RoChA, Mônica; SANTOS, Nereida Lucia Palkos dos; SILVA, ERminia; VIANNA, LEILA. O PESQUISADOR IN-MUNDO E O PROCESSO DE PRODUÇÃO DE OUTRAS formas de investigação em saúde. In: GOMES, Maria Paula Cerqueira; MERhy, Emerson Elias, organizadores. Pesquisadores In-Mundo: um estudo da produção do acesso e barreira em saúde mental. Porto Alegre: Editora ReDE UNIDA; 2014. P.155-70.

ADAMS, Tony. E.; JONES, Stacy; ElLiS, Carolyn. Autoethnografphy: understanding qualitative Research. OXford University Press, 2015.

BRASil. Secretaria de Direitos Humanos da Presidência da República, Secretaria Nacional de Promoção dos Direitos da Pessoa com Deficiência. Cartilha do Censo 2010: pessoas com deficiência. Brasília, DF; 2014. 29 p. BRASIL. LeI N 13.146, de 6 de JULHo de 2015. InStITUI A LeI BrasileIRA DE Inclusão da Pessoa com Deficiência). Diário Oficial da União [InTERnet]. 7 JUL. 2015. DISPONÍVEL EM: HTTP://WWW.PLANALTO.GOV.BR/CCIVIL_03/_ATO20152018/2015/LEI/L13146.HTM. ACESSO EM: 12 fEV. 2018.

Brasil. Ministério da Educação. Conselho Nacional de Educação. Câmara de Educação Superior. Diário Oficial da União. Resolução n ${ }^{\circ}$ 7, de 18 de DEZEMBRo de 2018. Brasília, DF, 2018, P. 49. Disponível EM: HTTP://WWW.IN.GOV.BR/MATERIA/-/ASSET_PUBLISHER/KUJRWOTZC2MB/CONTENT/ID/55877808. ACESSO EM: 18 NOV. 2020.

CAMPinas. Conselho Municipal dos Direitos das Pessoas com Deficiência. Relatório da X Conferência Municipal dos Direitos das Pessoa com Deficiência de Campinas. Campinas, SP: Conselho Municipal dos Direitos das Pessoas com DeficiênCIA; 2017. Disponível EM: htTP://WWW.CAMPINAS.SP.gOV. 
O Agir Militante em um Projeto de Extensão com a Comunidade Surda Nubia Garcia Vianna • Janice Gonçalves Temoteo Marques

BR/ARQUIVOS/DIREITOS-DEFICIENCIA/RELATORIO_FINAL_CONFERENCIA.PDF. ACESSO EM: 26 AGO. 2020.

CAMPinas. Conselho Municipal dos Direitos das Pessoas com Deficiência. Relatório Final da $11^{a}$ Conferência Municipal de Saúde de Campinas. Campinas, SP: Conselho Municipal de Saúde Campinas, 2019. Disponível EM: HTTP://WWW.SAUDE.CAMPINAS.SP.GOV.BR/SAUDE/CMS/CONF_MUN_SAUDE/11A_ CONFERENCIA/RELATORIO_FINAL_DA_11A_CONFERENCIA_MUNICIPAL_DE_SAUDE. PDF. ACESSO EM: 26 AgO. 2020.

CARVAlho, Alexandre Filordi de; MARTinS, Vanessa Regina de Oliveira. ANUNCIAÇÃO E INSURREIÇÃO DA DIFERENÇA SURDA: CONTRA-AÇÕES NA BIOPOLÍTICA DA educação bilíngue. Childhood \& Philosofy, vol. 12, N. 24, P. 391 - 415, 2016.

CHAVEIRO, NeUmA; RODRÍGUEZ-MARTIN, Dolors; FARIA JULIANA GUI23 marães. Educação bilíngue para surdos em Barcelona-Espanha. The SpeCIALIST. Vol, 41, N. 1, 2020. DisPONÍVEL EM: HTTPS://REVISTAS.PUCSP.BR/ESP/ ARTICLE/VIEW/42418. ACESSO EM: 18 NOV. 2020.

CERQueIRA, Paula; MERHY, Emerson; SILVA, Erminia; ABRAHÃo, Ana LÚCIA; VIANNA, LEILA; ROCHA, MôNICA; ET AL. UMA PESQUISA E SEUS ENCONTROS: A FABRICAÇÃO DE INTERCESSORES E O CONHECIMENTO COMO PRODUÇÃO. IN: Gomes, Maria Paula Cerqueira; Merhy, Emerson Elias, organizadores. Pesquisadores In-Mundo: um ESTUdo da PROdução do aCESSO E barReIRA em saúde mental. Porto Alegre: Editora Rede UNIDA, p.25-42, 2014.

foucault, Michel. O sujeito e o poder. In: Dreyfus H, Rabinow P. MiCHEL FOUCAULT: UMA TRAJETÓRIA FILOSÓFICA: PARA ALÉM DO ESTRUTURALISMO E DA HERmenêutica. Tradução: Carrero VP. Rio de Janeiro: Forense Universitária; 2010. iBgE - Instituto Brasileiro de Geografia e Estatística. Censo demográfico BRASILEIRO de 2010. Disponível EM: WWW. IBge.gov.Br. ACESSO EM: 18 nOV. 2020. 
O Agir Militante em um Projeto de Extensão com a Comunidade Surda Nubia Garcia Vianna • Janice Gonçalves Temoteo Marques

MAGAlhães, Célia Elisa Alves de. Autoetnografia em contexto pedagógiCO: ENTREVISTA E REUNIÃo COMO LÓCUS de INVESTIGAÇÃo. Veredas temáticas, PPG LINGUÍSTICA/UFJF - JUIZ DE FORA - ISSN: 1982-2243 2, Vol. 22, N. 1, 2018. MERHY, Emerson. O Conhecer Militante do Sujeito Implicado: o desafio de reconhecê-lo como saber válido. In: Franco, Túlio Batista; Peres, Marco Aurélio de Anselmo. Organizadores. Acolher Chapecó: uma experiência de mudança com base no processo de trabalho. São Paulo: HUCiTEC, 1 ed., P. 21-45, 2004.

OLiVeira, Fabiana de. Por uma terapêutica fonoaudiológica: os efeitos DO DISCURSO MÉDICO E DO DISCURSO PEDAGÓGICO NA CONSTITUIÇÃO DO DISCURSO FONOAUDIOLÓGICO. 2002. 187 P. DisSERTAÇÃo (DISSERTAÇÃO EM: EstudOS DA Linguagem). Instituto de Letras, Universidade Federal do Rio Grande do Sul; Porto Alegre, RS, 2002.

24

Reis, Marlene Barbosa de Freitas; MORais, Isadora Cristinny Vieria de. INCLUSÃO DOS SURDOS NO BRASIL: DO ORALISMO AO BILINGUISMO. REVISTA UFG.

DossIÊ - EXPERIÊNCIAS DE ENRIQUECIMENTO MÚtUO: DESDE E COM A COMUNIDADE SURDA. 20 (26), P. 1-31, 2020.

RODRÍGUEZ-MARTÍN, DOLORS; RIGOL-CUADRA, AsSUMPTA; CRESPO-MIRASOL, Esther; MAESTRE-GONZÁLEZ, Elena. Falta de AdeCUACIÓN DEL SISTEMA DE SALUD A GRUPOS MINORITARIOS Y MINORIZADOS: EL CASO DE LA Comunidad SORDA. In: JUBANY, O; GUASCH, O. (ORG.) Intersecciones ENCARNADAS: [CON]TEXTOS CRítICOS EN GÉNERO, IDENTIDAD Y DIVERSIDAD. BARCELONA, Editorial BellaterRa; P.55-84, 2020.

VIANNA, Nubia Garcia. Ruídos e siLêncios: uma análise genealógICA SObre A SURdeZ Na política de saúde bRAsileira. 2018. 231 P. Tese (Doutorado em: Saúde Coletiva). Faculdade de Ciências Médicas - FCM, Universidade Estadual de Campinas; Campinas, SP, 2018. 